\title{
Ensaios toxicológicos aplicados à análise de águas contaminadas por fármacos
}

\author{
Toxicological tests applied to the analysis of water contaminated by drugs
}

Cássia Cabral Souza' ${ }^{\oplus}$, Sergio Francisco Aquino² $₫$, Silvana de Queiroz Silva ${ }^{3 *} \oplus^{(1)}$

口-

\section{RESUMO}

Fármacos de diversas classes têm sido detectados no ambiente aquático nos últimos anos. A presença desses compostos químicos deve-se, sobretudo, ao lançamento de esgoto in natura ou à remoção incompleta durante as etapas do tratamento de esgoto. Embora tais materiais sejam detectados em baixas concentrações (ng. $\left..^{-1}-\mu \mathrm{g} . \mathrm{L}^{-1}\right)$, os impactos de alguns fármacos à biota aquática já são conhecidos, sendo os efeitos na saúde humana, especialmente aqueles relacionados à exposição crônica, ainda pouco conhecidos e/ou controversos. Ensaios biológicos são ferramentas valiosas para avaliar a toxicidade de fármacos aos organismos expostos, e a sua adoção conjunta aos ensaios de tratabilidade da água e efluentes permitiria preencher lacunas de conhecimento e a construção de consenso na literatura científica sobre os seus efeitos toxicológicos. Pelo exposto, este artigo de revisão apresenta uma visão geral da ocorrência de fármacos em amostras ambientais do país e a toxicidade observada por meio de diferentes ensaios biológicos.

Palavras-chave: fármacos; ecotoxicidade; toxicidade; microcontaminantes; contaminantes de preocupação emergente; qualidade de água.

\begin{abstract}
Drugs of several classes have been detected in the aquatic environment in recent years. The presence of these chemicals is mainly due to the discharge of raw sewage or to their incomplete removal in sewage treatment plants. Although they have been detected at low concentrations (ng. $\mathrm{L}^{-1}-\mu \mathrm{g} \cdot \mathrm{L}^{-1}$ ), the effects of pharmaceutical compounds on the aquatic biota are already acknowledged, being the effects on human health, especially those related to chronic exposure, still unknown and/or controversial. Biological assays are valuable tools for assessing drug toxicity to exposed organisms and their joint adoption in water and effluent treatability trials would fill up knowledge gaps and build consensus in the scientific literature on their toxicological effects. This review paper presents an overview of the occurrence of drugs in several Brazilian environmental samples and compiles the toxicity observed by means of different biological assays.
\end{abstract}

Keywords: drugs. ecotoxicity; toxicity; micropollutants; contaminants of emerging concern; water quality.

\section{FÁRMACOS NO AMBIENTE}

Fármacos, assim como novos pesticidas, produtos de cuidado/higiene pessoal, suplementos nutricionais, agentes de diagnóstico, entre outros compostos que têm sido detectados no ambiente e para os quais não há legislação estabelecendo padrões ou limites ambientais, são considerados contaminantes emergentes (BIRCH et al., 2015). Os produtos farmacêuticos e os de higiene pessoal têm recebido atenção de pesquisadores nos últimos anos por causa da intensa produção e, principalmente, do uso generalizado e contínuo em humanos e animais (DAUGHTON, 2002).

Os fármacos são classificados pela atividade biológica, estrutura química ou modo de ação. Quanto à atividade biológica, podem ser divididos em analgésicos, antitérmicos, anti-inflamatórios, antibióticos, anti-hipertensivos, hormônios etc. (KÜMMERER, 2010).
Os mecanismos de ação dos fármacos são diversificados, variando de acordo com a classe pertencente. Uma vez administradas, essas substâncias são absorvidas no organismo, sendo parcialmente metabolizadas e então excretadas nas formas original, associada ou como metabólitos. Quando essas substâncias são excretadas pela urina e fezes de seres humanos e animais, alcançam o esgoto doméstico e/ou os corpos d'água (BILA; DEZOTTI, 2003; MELO et al., 2009).

De fato, a principal rota de entrada de resíduos de fármacos no ambiente é o lançamento de esgotos domésticos, tratados ou in natura, nos cursos d'água. No caso dos fármacos consumidos pelo ser humano, parte deles entra no sistema aquático na forma inalterada ou como metabólito, após passagem pela estação de tratamento de esgotos, que remove apenas parcialmente a carga afluente de tais contaminantes (AQUINO; BRANDT; CHERNICHARO, 2013; GARTISER et al.,

Universidade Federal de Ouro Preto - Ouro Preto (MG), Brasil.

²Departamento de Química, Universidade Federal de Ouro Preto - Ouro Preto (MG), Brasil.

${ }^{3}$ Departamento de Ciências Biológicas, Universidade Federal de Ouro Preto - Ouro Preto (MG), Brasil.

*Autora correspondente: silvana@iceb.ufop.br

Recebido: 04/O8/2017 - Aceito: 26/O2/2019 - Reg. ABES: 183632 
2012; MELO et al., 2009). Além disso, deve-se considerar o descarte de efluentes hospitalares e de fármacos não consumidos ou fora do prazo de validade, incluindo os de uso veterinário, quando as drogas são deliberadamente introduzidas no ambiente (DELGADO et al., 2012; FARRÉ et al., 2008; TERNES et al., 2002).

Dados de monitoramento ambiental realizados no Brasil (LIMA et al., 2017) indicam que fármacos são encontrados em mananciais superficiais, principalmente aqueles pouco preservados, em concentrações que variam de dezenas a centenas de nanogramas por litro (ng. $\mathrm{L}^{-1}$ ). Para que fármacos e outros microcontaminantes não sejam encontrados na água potável, eles devem ser eficientemente removidos durante o tratamento de água, mas sabe-se que as operações unitárias (coagulação, floculação, sedimentação, filtração) utilizadas nas estações de tratamento de água (ETAs) são apenas moderadamente eficazes na remoção de tais poluentes (BENOTTI et al., 2009; BILA; DEZOTTI, 2003; LIMA et al., 2014; USEPA, 2001), fazendo com que a água tratada seja uma rota potencial de exposição humana a fármacos e outros contaminantes emergentes (MACHADO et al., 2016). Embora a etapa de desinfecção com cloro resulte normalmente na remoção (por oxidação) do fármaco-alvo, isso em geral ocorre com a formação de subprodutos oxidados cuja toxicidade é pouco conhecida (SOUZA et al., 2018). De fato, a formação de subprodutos da cloração de fármacos já foi observada para diclofenaco (QUINTANA et al., 2010; RIGOBELLO, 2012), metformina (QUINTÃO et al., 2016), sulfametoxazol (DODD; HUANG, 2004; SOUZA et al., 2018), 17 $\beta$-estradiol e estrona (PEREIRA, 2011), entre outros.

Em 2011, foram determinados os procedimentos e as responsabilidades relativos ao controle e à vigilância da qualidade da água para consumo humano e seu padrão de potabilidade por meio da Portaria no 2.914/2011, do Ministério da Saúde (BRASIL, 2011), posteriormente incorporada como Anexo XX da Portaria de Consolidação ${ }^{\circ}$ 5, de 28 de setembro de 2017, do referido ministério (BRASIL, 2017). Essa portaria, a exemplo do que se passa em outros países e coadunando-se com a versão mais atual dos guias de qualidade da água potável da Organização Mundial da Saúde (OMS, 2017), não estabelece valores de referência para a presença de fármacos na água potável. Embora alguns estudos de monitoramento realizados no Brasil indiquem a presença de tais contaminantes em mananciais de abastecimento e até mesmo em águas distribuídas à população (GHISELLI, 2006; GUIMARÃES, 2008; SODRÉ et al., 2010; JARDIM et al., 2011), é improvável que a exposição a eles pelo consumo de água cause significativos efeitos adversos, uma vez que esses compostos ocorrem em concentrações muito inferiores à dose terapêutica mínima. Por outro lado, a OMS (2012) salienta no documento Pharmaceuticals in DrinkingWater que há lacunas no conhecimento da avaliação de riscos associados à exposição a longo prazo a fármacos em baixas concentrações e ao possível efeito combinado de misturas de substâncias químicas, incluindo os fármacos.

$\mathrm{Na}$ mesma linha, outros documentos da OMS (BERGMAN et al., 2013; OMS, 2014) reconhecem a preocupação ambiental que se deve ter com fármacos que exibem atividade endócrina (desreguladores endócrinos) ou que induzam à resistência antimicrobiana (antibióticos).

Avanços nas técnicas analíticas têm contribuído para o aumento na detecção de fármacos e outros contaminantes de preocupação emergente na água (OMS, 2012). A seguir, são apresentados resultados de estudos de monitoramento de fármacos de diversas classes, em esgoto e águas naturais no Brasil (Tabela 1). De acordo com os dados, pode-se inferir que tanto no esgoto bruto quanto no efluente tratado há a presença de uma variada classe de fármacos indicando que algumas classes não são totalmente removidas durante o tratamento. Particularmente, a baixa eficiência ou a não remoção desses compostos em estações de tratamento de esgoto (ETE) foram observadas por diferentes grupos de pesquisa para o antilipêmico bezafibrato, o anti-inflamatório diclofenaco, os antibióticos trimetoprima e sulfametoxazol e o estrogênio sintético $17 \alpha$-etinilestradiol.

A presença de fármacos no esgoto tratado é determinante para a presença de tais contaminantes nos corpos d'água. Em uma revisão publicada por Carlsson et al. (2006), avaliou-se e classificou-se o risco ambiental de diversos produtos farmacêuticos, como diclofenaco, ciclofosfamida, enalapril, ibuprofeno e metformina. Das 27 substâncias testadas, nove (diclofenaco, etinilestradiol, ibuprofeno, metoprolol, noretisterona, oestriol, oxazepam, paracetamol e oxitetraciclina) foram consideradas perigosas para o ambiente aquático, considerando fatores como meia-vida, biodegradabilidade, ocorrência ambiental e estatísticas de vendas no país de estudo (Suécia).

Os estudos de monitoramento de fármacos em ETA são ainda incipientes, mas os dados divulgados na literatura sugerem que tais fármacos estão presentes em pequenas concentrações na água distribuída (Tabela 2). Assim, a presença desses compostos em mananciais de abastecimento ocorre com maior frequência e em maior concentração que nas águas distribuídas.

Vale ressaltar que a simples presença de fármacos no ambiente não significa, per se, risco à saúde humana e/ou à biota aquática. Idealmente, uma avaliação toxicológica deve ser feita de forma preliminar ou conjunta ao monitoramento químico para avaliar o risco ambiental de tais micropoluentes. A adoção de avaliação toxicológica vai ao encontro da recomendação feita pela OMS (2011) de investigar possíveis efeitos aditivos ou efeitos sinérgicos de misturas de fármacos e outras substâncias de modo a precisar se há risco potencial à saúde humana decorrente da exposição a tais contaminantes. Os próximos itens apresentam os principais testes de toxicidade que podem ser utilizados para cumprir tal objetivo. 
Tabela 1 - Estudos sobre a ocorrência de fármacos de diversas classes em esgoto bruto e em esgoto tratado em estações de tratamento de esgoto (ETEs) brasileiras.

\begin{tabular}{|c|c|c|c|c|c|}
\hline & Fármaco & Classe & Concentração $\left(\mu \mathrm{g} \cdot \mathrm{L}^{-1}\right)$ & Estado & Referência \\
\hline \multirow{18}{*}{ 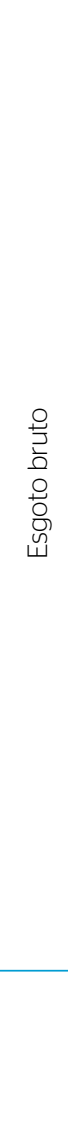 } & Ácido clofíbrico & $\begin{array}{c}\text { Principal metabólico de três } \\
\text { antilipêmicos }\end{array}$ & 1,0 & RJ & Stumpf et al. (1999) \\
\hline & \multirow[b]{2}{*}{ Bezafibrato } & \multirow[b]{2}{*}{ Antilipêmico } & 1,2 & RJ & Stumpf et al. (1999) \\
\hline & & & $<0,0043$ a 0,249 & MG & $\begin{array}{l}\text { Brandt et al. (2013) } \\
\text { Queiroz et al. (2012) }\end{array}$ \\
\hline & \multirow{4}{*}{ Diclofenaco } & \multirow{4}{*}{ Anti-inflamatório não esteroidal } & 0,8 & RJ & Stumpf et al. (1999) \\
\hline & & & 2,9 & SP & Ghiselli (2006) \\
\hline & & & $<0,007$ a 0,240 & MG & $\begin{array}{l}\text { Brandt et al. (2013) } \\
\text { Queiroz et al. (2012) }\end{array}$ \\
\hline & & & $<0,4$ a 5,6 & CE & Souza (2011) \\
\hline & \multirow{2}{*}{ Dipirona } & \multirow{2}{*}{ Analgésico } & 36,4 & SP & Ghiselli (2006) \\
\hline & & & $<2,2$ a 8,9 & CE & Souza (2011) \\
\hline & \multirow{5}{*}{$17 \alpha$-Etinilestradiol ${ }^{1}$} & \multirow{5}{*}{ Inibidor da ovulação } & 0,005 & RJ & Ternes et al. (1999) \\
\hline & & & 5,8 & SP & Ghiselli (2006) \\
\hline & & & $<0,0124$ & MG & Brandt et al. (2013) \\
\hline & & & $<12,4 \mathrm{a}<41,3$ & MG & Queiroz et al. (2012) \\
\hline & & & $<0,020$ a 5,2 & CE & Souza (2011) \\
\hline & Ibuprofeno & Anti-inflamatório não esteroidal & 54,2 & SP & Ghiselli (2006) \\
\hline & Paracetamol & Analgésico & 18 & SP & Ghiselli (2006) \\
\hline & Sulfametoxazol & Antibiótico & $<0,0019$ a 0,151 & MG & $\begin{array}{l}\text { Brandt et al. (2013) } \\
\text { Queiroz et al. (2012) }\end{array}$ \\
\hline & Trimetropina & Antibiótico & 0,023 a 0,114 & MG & $\begin{array}{l}\text { Brandt et al. (2013) } \\
\text { Queiroz et al. (2012) }\end{array}$ \\
\hline \multirow{18}{*}{ 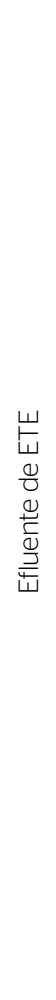 } & \multirow{3}{*}{ Bezafibrato } & \multirow{3}{*}{ Antilipêmicos } & 1,0 & RJ & Stumpf et al. (1999) \\
\hline & & & $<4,3$ a 309 & MG & Brandt et al. (2013) \\
\hline & & & $<4,3$ a 249 & MG & Queiroz et al. (2012) \\
\hline & \multirow{4}{*}{ Diclofenaco } & \multirow{4}{*}{ Anti-inflamatório não esteroidal } & 0,02 a 0,06 & RJ & Stumpf et al. (1999) \\
\hline & & & 1,8 & SP & Ghiselli (2006) \\
\hline & & & $<0,007$ a 0,755 & MG & Brandt et al. (2013) \\
\hline & & & $<0,4$ a 1,9 & CE & Souza (2011) \\
\hline & \multirow{2}{*}{ Dipirona } & \multirow{2}{*}{ Analgésico } & 23,7 & SP & Ghiselli (2006) \\
\hline & & & $<2,2$ a 1,3 & CE & Souza (2011) \\
\hline & \multirow{3}{*}{$17 \alpha$-Etinilestradiol } & \multirow{3}{*}{ Inibidor da ovulação } & 5,4 & $\mathrm{SP}$ & Ghiselli (2006) \\
\hline & & & $<0,0124$ & MG & $\begin{array}{l}\text { Brandt et al. (2013) } \\
\text { Queiroz et al. (2012) }\end{array}$ \\
\hline & & & $<0, \mathrm{O} 2 \mathrm{O}$ a 1,2 & CE & Souza (2011) \\
\hline & Ibuprofeno & Anti-inflamatório não esteroidal & 48,4 & SP & Ghiselli (2006) \\
\hline & Paracetamol & Analgésico & 5,9 & SP & Ghiselli (2006) \\
\hline & \multirow{2}{*}{ Sulfametoxazol } & \multirow{2}{*}{ Antibiótico } & $<0,0019$ a 0,124 & MG & Brandt et al. (2013) \\
\hline & & & $<0,0019$ a 0,161 & $M G$ & Queiroz et al. (2012) \\
\hline & \multirow{2}{*}{ Trimetropina } & \multirow{2}{*}{ Antibiótico } & $<0,001$ a 0,075 & MG & Brandt et al. (2013) \\
\hline & & & $<1$ a 88 & MG & Queiroz et al. (2012) \\
\hline
\end{tabular}

'Classificação de acordo com Kolpin et al. (2002). 


\section{TESTES DE TOXICIDADE AQUÁTICA}

Quando fármacos são liberados no ambiente por meio do lançamento de efluentes (industrial, rural ou doméstico), ou como resultado do descarte inadequado de drogas fora do prazo de validade, eles podem permanecer na forma original ou ser convertidos em produtos da transformação sob fotólise, oxidação e outros processos. Tanto os fármacos inalterados como os produtos da transformação podem ser bioativos e causar efeitos negativos em seres humanos e outros seres vivos (LI et al., 2015). Além disso, a poluição dos corpos d'água por fármacos e a ampla distribuição desses compostos no ambiente podem aumentar o risco de toxicidade, principalmente aos organismos aquáticos.

Com o intuito de investigar o risco decorrente da presença de poluentes ambientais, análises químicas e testes biológicos são continuamente desenvolvidos e empregados para quantificar os poluentes e avaliar os seus efeitos adversos (PARRELLA et al., 2013). Métodos analíticos são fundamentais para detectar e quantificar microcontaminantes no ambiente (BISTAN et al., 2012) enquanto os ensaios biológicos (in vitro ou in vivo) fornecem informações sobre os efeitos causados pelas substâncias no meio, servindo como uma complementação valiosa à análise química.

Tabela 2 - Estudos sobre a ocorrência de fármacos de diversas classes em mananciais e águas tratadas em estações de tratamento de água (ETAs) brasileiras.

\begin{tabular}{|c|c|c|c|c|c|}
\hline & Fármaco & Classe & Concentração $\left(\mu \mathrm{g} \cdot \mathrm{L}^{-1}\right)$ & Estado & Referência \\
\hline \multirow{17}{*}{ 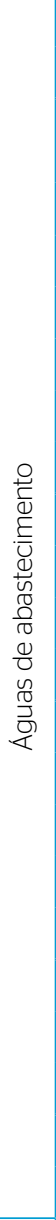 } & \multirow{2}{*}{ Ácido acetilsalicílico } & \multirow{2}{*}{ Anti-inflamatório não esteroidal } & 12,21 a 20,96 & SP & Raimundo (2007) \\
\hline & & & 0,5 a 21 & SP & Montagner e Jardim (2011) \\
\hline & Bezafibrato & Antilipêmicos & 0,025 & RJ & Stumpf et al. (1999) \\
\hline & \multirow{4}{*}{ Cafeína } & \multirow{4}{*}{ Estimulante } & 1,73 a 2,57 & RS & \multirow{4}{*}{$\begin{array}{l}\text { Machado et al. (2016) } \\
\text { Montagner e Jardim (2011) } \\
\text { Raimundo (2007) }\end{array}$} \\
\hline & & & 0,02 a 0,25 & SP & \\
\hline & & & 1,1 a 41,5 & SP & \\
\hline & & & 0,2 a 127 & SP & \\
\hline & \multirow{2}{*}{ Diclofenaco } & \multirow{2}{*}{ Anti-inflamatório não esteroidal } & 2 a 6 & SP & Ghiselli (2006) \\
\hline & & & $<0,14$ a 0,106 & SP & Montagner e Jardim (2011) \\
\hline & \multirow{5}{*}{$17 \alpha$-Etinilestradiol } & \multirow{5}{*}{ Inibidor da ovulação } & 0,106 a 4,39 & SP & Raimundo (2007) \\
\hline & & & 1,2 a 3,5 & SP & Ghiselli (2006) \\
\hline & & & 0,002 a 0,054 & MG & Moreira et al. (2009) \\
\hline & & & 0,005 a 0,064 & MG & Moreira et al. (2011) \\
\hline & & & $<0,17$ a 4,3 & SP & Montagner e Jardim (2011) \\
\hline & \multirow{3}{*}{ Ibuprofeno } & \multirow{3}{*}{ Anti-inflamatório não esteroidal } & 0,01 & RJ & Stumpf et al. (1999) \\
\hline & & & $<22,3$ & SP & Ghiselli (2006) \\
\hline & & & $<0,51$ & SP & Montagner e Jardim (2011) \\
\hline \multirow{4}{*}{ 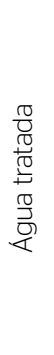 } & Paracetamol & Analgésico & nd & \multirow[t]{2}{*}{ SP } & \multirow[t]{2}{*}{ Ghiselli (2006) } \\
\hline & Ibuprofeno & Anti-inflamatório não esteroidal & nd & & \\
\hline & \multirow{2}{*}{$17 \alpha$-Etinilestradiol } & \multirow{2}{*}{ Inibidor da ovulação } & 1,7 & SP & Ghiselli (2006) \\
\hline & & & nd & SP & Jardim et al. (2011) \\
\hline
\end{tabular}

'Classificação de acordo com Kolpin et al. (2002); nd: não detectado. 
Os testes de toxicidade aguda e crônica são amplamente utilizados para avaliar os efeitos de substâncias sobre os organismos no ambiente aquático (COSTA et al., 2008; FERRARI et al., 2003; ISIDORI et al., 2005). Os testes de toxicidade aguda são utilizados para medir os efeitos de agentes tóxicos sobre espécies aquáticas durante um curto período de tempo em relação ao período de vida do organismo-teste e permitem a determinação de valores de concentração efetiva média $\left(\mathrm{CE}_{50}\right)$ e concentração letal média $\left(\mathrm{CL}_{50}\right)$ (COSTA et al., 2008). Por sua vez, testes de toxicidade crônica são realizados para medir os efeitos de substâncias químicas em espécies aquáticas por um período que pode abranger parte do ciclo de vida do organismo-teste ou todo esse ciclo, e os seus resultados são geralmente expressos como concentração de efeito não observado (CENO) ou concentração de efeito observado (CEO), mas também como $\mathrm{CE}_{50}$ (COSTA et al., 2008).

$\mathrm{Na}$ literatura da área podem ser encontrados testes de toxicidade aquática, agudos e crônicos, empregados para avaliar o potencial tóxico de diversas classes de fármacos com organismos-teste distintos, como visto na Tabela 3 .

Isidori et al. (2005) adotaram diversos testes de toxicidade aguda e crônica para avaliar os efeitos de diferentes antibióticos (Tabela 3). Segundo os autores, os ensaios crônicos são mais apropriados para detectar os impactos de fármacos em relação aos agudos, pois os efeitos foram constatados em concentrações de fármacos na ordem de $\mu \mathrm{g} . \mathrm{L}^{-1}$, enquanto os agudos, somente na ordem de mg. $\mathrm{L}^{-1}$.

Além disso, a escolha do organismo a ser usado pode influenciar na informação gerada. Por exemplo, Ferrari et al. (2003), avaliando a toxicidade aguda do diclofenaco com a bactéria marinha Vibrio fischeri e os crustáceos Daphnia magna e Ceriodaphnia dubia, revelaram que a bactéria marinha foi mais sensível ao fármaco quando comparada com os demais, enquanto o teste de toxicidade crônica revelou que das espécies estudadas a C. dubia foi a mais sensível (Tabela 3 ).

Testes de toxicidade aguda foram empregados com o microcrustáceo D. magna, a alga Desmodesmus subspicatus e a macrófita Lemna minor para diferentes fármacos (CLEUVERS, 2003) (Tabela 3). Os efeitos dos fármacos foram classificados de acordo com as diretrizes da Comissão das Comunidades Europeias (1996) (EU-Directive 93/67/ $\mathrm{EEC})$, que consideram um composto muito tóxico quando o valor de $\mathrm{CE}_{50}$ é menor que $1 \mathrm{mg} . \mathrm{L}^{-1}$; tóxico, de 1 a $10 \mathrm{mg}$. $\mathrm{L}^{-1}$; e perigoso, de 10 a $100 \mathrm{mg} \cdot \mathrm{L}^{-1}$. Com base nessa classificação, nenhum composto foi muito tóxico para as espécies analisadas. No geral, a toxicidade dos fármacos testados foi heterogênea entre as espécies, e a macrófita foi a mais sensível com base nos valores de $\mathrm{CE}_{50}$. CLEUVERS destacou ainda que, embora os efeitos agudos sejam algumas vezes improváveis quando os compostos são testados individualmente, o estudo da combinação dos efeitos é um fator de extrema importância, mesmo quando a toxicidade da substância é baixa, para obter uma melhor avaliação do potencial ecotoxicológico das substâncias no ambiente aquático.

Segundo a classificação EU-Directive 93/67/EEC supracitada, Nieto et al. (2016) observaram que o diclofenaco é tóxico para o crustáceo Atyaephyra desmarestii e que o ibuprofeno e a carbamazepina são perigosos. A resposta letal $\left(\mathrm{CL}_{50}\right)$ foi avaliada a 25 (Tabela 3) e a $20^{\circ} \mathrm{C} \mathrm{e}$ indicou que o aumento da temperatura pode maximizar a toxicidade aos organismos aquáticos.

Rozas et al. (2016) avaliaram a toxicidade aguda de fármacos individualmente e em mistura - no segundo caso, após tratamento com $\mathrm{UV} / \mathrm{H}_{2} \mathrm{O}_{2}$. $\mathrm{A} \mathrm{CL}_{50}$ em D. magna foi determinada para os fármacos diclofenaco e triclosan (Tabela 3). A utilização de um processo oxidativo avançado como $\mathrm{UV} / \mathrm{H}_{2} \mathrm{O}_{2}$ para amostras de água foi justificada pelo fato de métodos tradicionais de tratamento não serem eficientes para a remoção de fármacos. Dada a possibilidade de formação de subprodutos nesses processos, os autores avaliaram ainda os efeitos das misturas de fármacos após tratamento com $\mathrm{UV} / \mathrm{H}_{2} \mathrm{O}_{2}$. Os dados obtidos indicaram que os subprodutos da oxidação podem ser mais tóxicos que o fármaco individualmente. Além disso, observou-se que na mistura contendo triclosan houve $100 \%$ de imobilização de D. magna antes e depois do tratamento com $\mathrm{UV} / \mathrm{H}_{2} \mathrm{O}_{2}$.

A diferença na resposta entre espécies também foi constatada por Magdaleno, Carusso e Moretton (2017), que testaram a toxicidade de antimicrobianos em duas espécies de algas. Embora todos os fármacos testados tenham inibido o crescimento algal, a alga Pseudokirchneriella subcapitata foi a mais sensível (Tabela 3). Segundo Sanderson et al. (2004), antibióticos são considerados os fármacos mais perigosos, uma vez que podem levar à resistência microbiana, o que, segundo a OMS (2016), se configura como uma séria ameaça à saúde pública global e requer ação de setores governamentais e de toda a sociedade.

\section{TESTES DE GENOTOXICIDADE}

Uma ferramenta para avaliar o potencial genotóxico de compostos é a aplicação do teste SOS cromoteste, que utiliza bactérias Escherichia coli geneticamente modificadas, denominadas de PQ37. O teste in vitro é um ensaio colorimétrico que se baseia na expressão da enzima $\beta$-galactosidase e na resposta aos ataques de mutagênicos pela exclusão da capacidade de reparo de ácido desoxirribonucleico (DNA) (DEODATO, 2009). Isidori et al. (2005) testaram a genotoxicidade de antibióticos e observaram resposta positiva apenas para a ofloxacina no SOS cromoteste (Tabela 4).

O teste com Allium cepa baseia-se no contato direto de raízes da cebola com as amostras contendo os compostos tóxicos, com o objetivo de avaliar a citogenotoxicidade medida pelas alterações cromossômicas e de divisão das células meristemáticas dessa estrutura vegetal. 
Tabela 3 - Valores de $\mathrm{CL}_{50}$ e concentração efetiva média $\left(\mathrm{CE}_{50}\right)$ obtidos para fármacos em testes de toxicidade aguda e crônica.

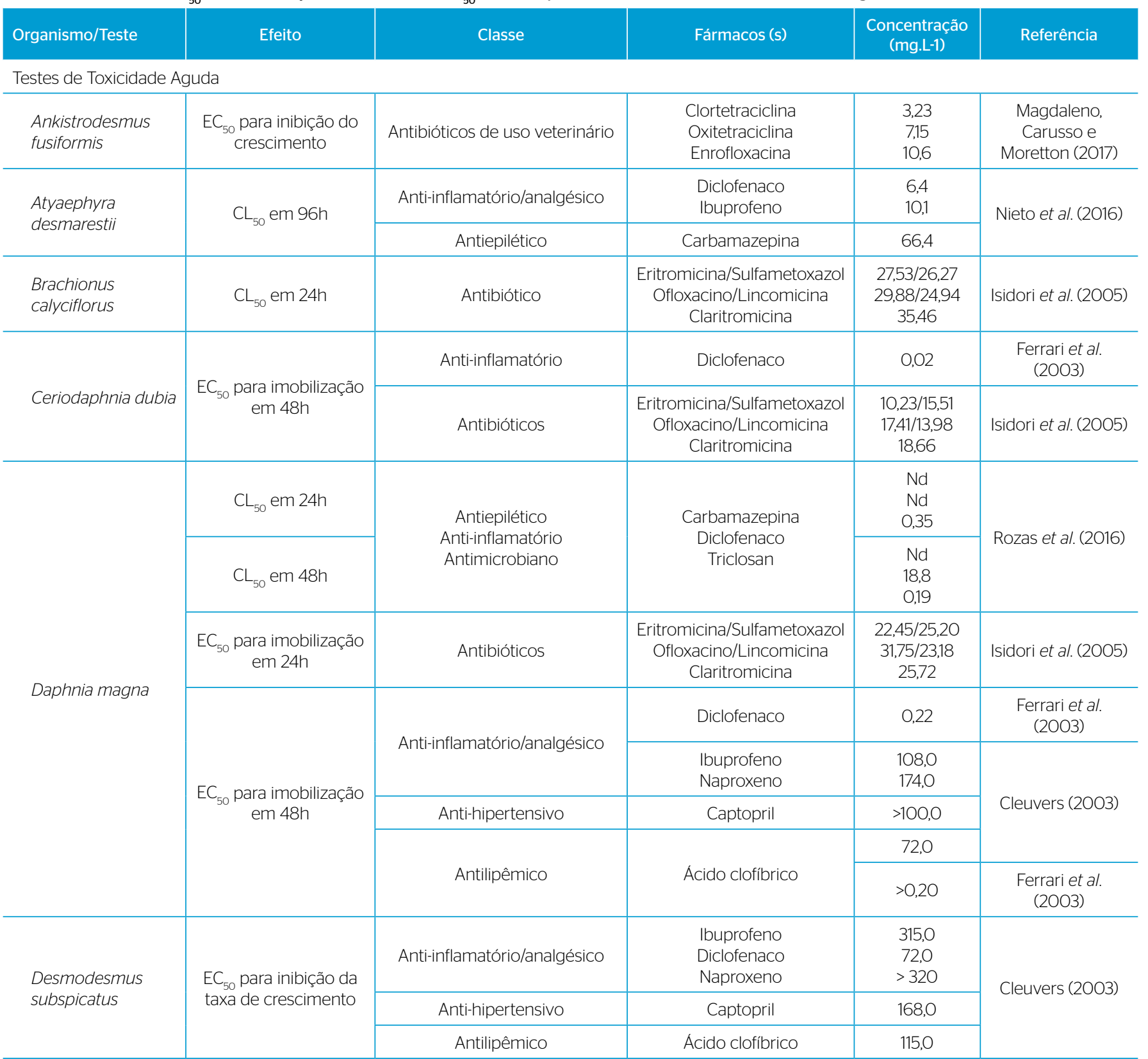

Testes de toxicidade aguda

\begin{tabular}{|c|c|c|c|c|c|}
\hline \multirow{3}{*}{ Lemna minor } & \multirow{3}{*}{$\begin{array}{l}\mathrm{EC}_{50} \text { para inibição da } \\
\text { taxa de crescimento }\end{array}$} & $\begin{array}{l}\text { Anti-inflamatório } \\
\text { Analgésico }\end{array}$ & $\begin{array}{c}\text { Ibuprofeno } \\
\text { Diclofenaco } \\
\text { Naproxeno } \\
\end{array}$ & $\begin{array}{c}22,0 \\
7,5 \\
24,2 \\
\end{array}$ & \multirow{3}{*}{$\begin{array}{l}\text { Cleuvers } \\
\text { (2003) }\end{array}$} \\
\hline & & Anti-hipertensivo & Captopril & 25,0 & \\
\hline & & Antilipêmico & Ácido clofíbrico & 12,5 & \\
\hline $\begin{array}{l}\text { Pseudokirchneriella } \\
\text { subcapitata }\end{array}$ & $\begin{array}{l}\mathrm{EC}_{50} \text { para inibição do } \\
\text { crescimento }\end{array}$ & Antibióticos de uso veterinário & $\begin{array}{l}\text { Clortetraciclina } \\
\text { Oxitetraciclina } \\
\text { Enrofloxacina }\end{array}$ & $\begin{array}{c}1,19 \\
0,92 \\
5,18\end{array}$ & $\begin{array}{c}\text { Magdaleno, } \\
\text { Carusso e } \\
\text { Moretton } \\
\text { (2017) }\end{array}$ \\
\hline \multirow[t]{2}{*}{ Vibrio fischeri } & \multirow[t]{2}{*}{$\begin{array}{l}\mathrm{EC}_{50} \text { para redução da } \\
\text { luminescência }\end{array}$} & Antibióticos & $\begin{array}{c}\text { Eritromicina } \\
\text { Sulfametoxazol } \\
\text { Ofloxacino } \\
\text { Lincomicina } \\
\text { Claritromicina }\end{array}$ & $\begin{array}{c}\text { Sem efeito até } 100 \\
23,30 \\
25 \% \text { inibição a } 100 \\
\text { sem efeito até } 100 \\
\text { sem efeito até } 100\end{array}$ & $\begin{array}{l}\text { Isidori et al. } \\
\text { (2005) }\end{array}$ \\
\hline & & Anti-inflamatório & Diclofenaco & 0,01 & $\begin{array}{l}\text { Ferrari et al. } \\
\quad(2003)\end{array}$ \\
\hline
\end{tabular}


Tabela 3 - Continuação.

\begin{tabular}{|c|c|c|c|c|c|}
\hline Organismo/Teste & Efeito & Classe & Fármacos (s) & $\begin{array}{l}\text { Concentração } \\
\text { (mg.L-1) }\end{array}$ & Referência \\
\hline \multicolumn{6}{|c|}{ Testes de toxicidade crônica } \\
\hline \multirow{2}{*}{$\begin{array}{l}\text { Brachionus } \\
\text { calyciflorus }\end{array}$} & $\begin{array}{l}\text { Alteração da } \\
\text { reprodução após 48h }\end{array}$ & Anti-inflamatório & Diclofenaco & $\begin{array}{l}\text { CENO 0,012 } \\
\text { CEO 0,025 }\end{array}$ & $\begin{array}{l}\text { Ferrari et al. } \\
\quad(2003)\end{array}$ \\
\hline & $\begin{array}{c}\text { Inibição do } \\
\text { crescimento em 48h }\end{array}$ & Antibióticos & $\begin{array}{c}\text { Eritromicina/Sulfametoxazol } \\
\text { Ofloxacino/Lincomicina } \\
\text { Claritromicina }\end{array}$ & $\begin{array}{c}0,94 / 9,63 \\
0,53 / 0,68 \\
12,21\end{array}$ & $\begin{array}{l}\text { Isidori et al. } \\
\text { (2005) }\end{array}$ \\
\hline \multirow{2}{*}{$\begin{array}{l}\text { Ceriodaphnia } \\
\text { dubia }\end{array}$} & $\begin{array}{l}\text { Inibição da } \\
\text { reprodução após sete } \\
\text { dias }\end{array}$ & Anti-inflamatório & Diclofenaco & $\begin{array}{l}\text { CENO 0,001 } \\
\text { CEO 0,002 }\end{array}$ & $\begin{array}{l}\text { Ferrari et al. } \\
\quad(2003)\end{array}$ \\
\hline & $\begin{array}{c}\text { Inibição do } \\
\text { crescimento após sete } \\
\text { dias }\end{array}$ & Antibióticos & $\begin{array}{c}\text { Eritromicina/Sulfametoxazol } \\
\text { Ofloxacino/Lincomicina } \\
\text { Claritromicina }\end{array}$ & $\begin{array}{l}0,22 / 0,21 \\
3,12 / 7,20 \\
8,16\end{array}$ & $\begin{array}{l}\text { Isidori et al. } \\
\text { (2005) }\end{array}$ \\
\hline \multirow{2}{*}{$\begin{array}{l}\text { Pseudokirchneriella } \\
\text { subcapitata }\end{array}$} & $\begin{array}{c}\text { Inibição do } \\
\text { crescimento após 96h } \\
\text { de exposição }\end{array}$ & Anti-inflamatório & Diclofenaco & $\begin{array}{l}\text { CENO 0,01 } \\
\text { CEO O,02 }\end{array}$ & $\begin{array}{l}\text { Ferrari et al. } \\
\quad(2003)\end{array}$ \\
\hline & $\begin{array}{l}\text { Inibição do } \\
\text { crescimento em 72h }\end{array}$ & Antibióticos & $\begin{array}{c}\text { Eritromicina/Sulfametoxazol } \\
\text { Ofloxacino/Lincomicina } \\
\text { Claritromicina }\end{array}$ & $\begin{array}{c}0,02 \mathrm{O} / \mathrm{O}, 52 \\
1,44 / 0,07 \\
0,0020\end{array}$ & $\begin{array}{l}\text { Isidori et al. } \\
\text { (2005) }\end{array}$ \\
\hline
\end{tabular}

$\mathrm{CE}_{50}$ : Nd: Não determinado; CENO: concentração de efeito não observado; $\mathrm{CEO}$ : concentração de efeito observado.

Um estudo com as drogas antirretrovirais zidovudina e nevirapina demonstrou que os dois fármacos inibem o crescimento em comprimento da raiz, além de induzirem mudanças no índice mitótico e aberrações cromossômicas em A. cepa (ONWUAMAH et al., 2014), conforme apresentado na Tabela 4.

O ensaio cometa é um teste toxicogenético para avaliar lesões genômicas. Células com o DNA danificado apresentam o formato de um cometa quando colocadas em agarose e submetidas à eletroforese (TICE et al., 2000). O antibiótico trimetropina foi testado quanto ao seu potencial de induzir danos no DNA. Percebeu-se esse efeito em linfócitos humanos em concentrações específicas, como mostrado na Tabela 4 (ABOU-EISHA, 2006). Já a cafeína induziu danos no DNA de eritrócitos do peixe Prochilodus lineatus, e o aumento do dano foi proporcional à concentração do fármaco (SANTOS-SILVA; MONTAGNER; MARTINEZ, 2018).

Um teste para avaliar a presença e a extensão de danos cromossômicos em células expostas a agentes genotóxicos é o de micronúcleos (MN) (BONASSI et al., 2007; HOSSEINIMEHR; KARAMI, 2005). Efeitos mutagênicos, expressos pela formação de micronúcleos, já foram observados com os antibióticos adriamicina (AL-HARBI, 1993), ciclofosfamida (HOSSEINIMEHR; KARAMI, 2005) e indometacina (DEVI; POLASA, 1987) (Tabela 4). Magdaleno, Carusso e Moretton (2017) avaliaram a genotoxicidade de antibióticos de uso veterinário pelo teste de MN. Dos fármacos testados, apenas a enrofloxacina induziu à formação de $\mathrm{MN}$ em células de $A$. cepa (Tabela 4).

Por sua vez, para avaliação da mutagenicidade, o teste de troca entre cromátides-irmãs (TCI), traduzido do inglês, sister chromatid exchange assay (SCE), tem sido aplicado. O ensaio identifica o potencial de mutagenicidade cromossômica de agentes químicos por meio do dano no DNA (STULTS; KILLEN; PIERCE, 2014) pela recombinação mitótica. Uma investigação do potencial do analgésico paracetamol de induzir danos no DNA em células da medula óssea de camundongos demonstrou que, além de provocar aberrações cromossômicas, tal fármaco aumentou a frequência da troca entre cromátides-irmãs (GIRI; SIVAM; KHAN, 1992). Tal efeito também foi notado para três diferentes anti-inflamatórios (ibuprofeno, naproxeno e cetoprofeno) usando células da medula óssea (PHILIPOSE et al., 1997) (Tabela 4).

O ensaio Salmonella/microssoma (teste de Ames) também é amplamente utilizado para avaliar a mutagenicidade de diversos compostos, entre eles fármacos, utilizando cepas da bactéria Salmonella typhimurium. O analgésico dipirona já foi avaliado pelo teste de Ames com cepas TA98 e TA100 da referida bactéria (IZUMI et al., 1991), o que mostrou que a dipirona é fracamente mutagênica para a cepa TA100 na presença e na ausência de metabolização. Isidori et al. (2005) testaram a mutagenicidade de seis antibióticos pelo teste de Ames e, entre eles, três foram mutagêni$\cos$ (Tabela 4). Sulfametoxazol e lincomicina induziram à atividade mutagênica nas cepas TA98 e TA100, enquanto ofloxacina foi mutagênica apenas na cepa TA98.

\section{TESTES DE CITOTOXICIDADE}

Um dos métodos para avaliar a citotoxicidade envolve a quantificação dos danos e da integridade da membrana celular. Quando uma célula é danificada, ocorre liberação da enzima intracelular lactato desidrogenase (LHD) para o sobrenadante celular, resultando em diminuição da viabilidade celular. O efeito do fármaco amiodarona (antiarrítmico) 
sobre a liberação de LDH em mitocôndrias demonstrou que a substância inibiu a atividade dessas enzimas com uma relação dose-dependente, expondo sua citotoxicidade por meio de danos na membrana (DZIMIRI; ALMOTREFI, 1993) (Tabela 4).

Para avaliar a citotoxicidade de compostos individuais ou misturas complexas, por meio da conversão celular de um substrato em produto cromogênico, o ensaio colorimétrico denominado de MTT foi desenvolvido por Mosmann (1983) e é possivelmente um dos mais versáteis e empregados na literatura. O ensaio baseia-se na medida do dano induzido pelo composto/extrato no metabolismo celular de glicídios, usualmente pela avaliação da atividade de desidrogenases mitocondriais. Essas enzimas são funcionais apenas em células vivas e reduzem bioquimicamente o MTT
(3-(4,5-dimetiltiazol-2-il)-2,5-difenil-2H tetrazolato de bromo) ao produto violácea e insolúvel em água conhecido como formazan (1-(4,5-dimetiltiazol-2-il)-3,5-difenilformazan), que pode ser quantificado pela colorimetria.

O ensaio do MTT foi empregado por Allen et al. (1991) para avaliar a citotoxicidade de oito anti-inflamatórios não esteroidais (indometacina, ácido mefenâmico, cetoprofeno, ibuprofeno, sulindaco, aspirina, fenilbutazona e naproxeno) em células de adenocarcinoma ileocecal humana (HCT-8). Os anti-inflamatórios foram testados em concentrações de $10 \mu \mathrm{M}$ a $10 \mathrm{mM}$, e foi observado que até $1 \mathrm{mM}$ nenhum dos fármacos induziu a efeitos citotóxicos, embora todos eles tenham induzido a efeitos tóxicos na maior concentração testada (10 mM) (Tabela 4$)$.

Tabela 4 - Resultados de testes de genotoxicidade e citotoxicidade para fármacos.

\begin{tabular}{|c|c|c|c|c|c|c|}
\hline Organismo-teste & Efeito & Classe & Fármaco(s) & $\begin{array}{l}\text { Concentração } \\
\left.\text { (mg. } \mathrm{L}^{-1}\right)\end{array}$ & Parâmetro & Referência \\
\hline \multicolumn{7}{|c|}{ Testes de genotoxicidade } \\
\hline Allium cepa & $\begin{array}{c}\text { Alteração } \\
\text { cromossômica e } \\
\text { da divisão celular }\end{array}$ & Antirretrovirais & $\begin{array}{l}\text { Zidovudina } \\
\text { Nevirapina }\end{array}$ & $\begin{array}{l}170 \\
250\end{array}$ & - & $\begin{array}{l}\text { Onwuamah et al. } \\
\text { (2014) }\end{array}$ \\
\hline \multirow[b]{2}{*}{ Teste cometa } & \multirow[b]{2}{*}{$\begin{array}{l}\text { Formação do } \\
\text { cometa }\end{array}$} & Antibiótico & Trimetropina & $25-150 \mu \mathrm{g} / \mathrm{mL}$ & - & Abou-Eisha (2006) \\
\hline & & Estimulante & Cafeína & $0,0003-0,03$ & - & $\begin{array}{l}\text { Santos-Silva, } \\
\text { Montagner e } \\
\text { Martinez (2018) }\end{array}$ \\
\hline \multirow{4}{*}{$\begin{array}{l}\text { Teste de } \\
\text { micronúcleos }\end{array}$} & \multirow{4}{*}{$\begin{array}{l}\text { Formação de } \\
\text { micronúcleos }\end{array}$} & Antibiótico & Adriamicina & Efeitos com 15 mg & - & Al-Harbi (1993) \\
\hline & & Anticâncer & Ciclofosfamida & Efeitos com 50 mg & - & $\begin{array}{l}\text { Hosseinimehr \& } \\
\text { Karami (2005) }\end{array}$ \\
\hline & & Anti-inflamatório & Indometacina & Efeitos com 36 mg & - & Devi e Polasa (1987) \\
\hline & & $\begin{array}{l}\text { Antibiótico de } \\
\text { uso veterinário }\end{array}$ & Enrofloxacina & $1-10$ & - & $\begin{array}{c}\text { Magdaleno, } \\
\text { Carusso e Moretton } \\
\text { (2017) }\end{array}$ \\
\hline $\begin{array}{l}\text { Escherichia } \\
\text { coli PQ37 }\end{array}$ & $\begin{array}{l}\text { Mudança da cor } \\
\text { do meio }\end{array}$ & Antibiótico & $\begin{array}{c}\text { Eritromicina } \\
\text { Sulfametoxazol } \\
\text { Ofloxacino } \\
\text { Lincomicina } \\
\text { Claritromicina }\end{array}$ & - & $\begin{array}{c}0,84 \pm 0,06 \\
1,63 \pm 0,18 \\
78 \pm 7,21 \\
1,46 \pm 0,08 \\
1,20 \pm 0,17\end{array}$ & Isidori et al. (2005) \\
\hline $\begin{array}{l}\text { Salmonella } \\
\text { typhimurium } \\
\text { TA98 / TA100 }\end{array}$ & $\begin{array}{l}\text { Deslocamento do } \\
\text { quadro de leitura } \\
\text { / Substituição dos } \\
\text { pares de bases }\end{array}$ & Antibiótico & $\begin{array}{c}\text { Sulfametoxazol } \\
\text { Ofloxacino } \\
\text { Lincomicina }\end{array}$ & - & $\begin{array}{c}2,7 \pm 0,95^{\star *} / 0,2 \pm \\
0,09 \\
130,8 \pm 18,23 / \mathrm{ns} \\
2,9 \pm 1,13 / 0,3 \pm 0,14\end{array}$ & Isidori et al. (2005) \\
\hline $\begin{array}{l}\text { Troca entre } \\
\text { cromátides- } \\
\text { irmãs }\end{array}$ & $\begin{array}{c}\text { Dano no DNA pela } \\
\text { recombinação } \\
\text { mitótica }\end{array}$ & Anti-inflamatório & $\begin{array}{l}\text { Ibuprofeno } \\
\text { Ketoprofeno } \\
\text { Naproxeno } \\
\text { Paracetamol }\end{array}$ & - & $\begin{array}{c}50-100 \mathrm{mg} / \mathrm{kg} \\
50-100 \mathrm{mg} / \mathrm{kg} \\
100 \mathrm{mg} / \mathrm{kg} \\
50-400 \mathrm{mg}\end{array}$ & $\begin{array}{l}\text { Philipose et al. } \\
\text { (1997) }\end{array}$ \\
\hline \multicolumn{7}{|c|}{ Testes de citotoxicidade } \\
\hline $\begin{array}{l}\text { Teste lactato } \\
\text { desidrogenase } \\
(\mathrm{LDH})\end{array}$ & $\begin{array}{l}\text { Oxidação de } \\
\text { NADH a NAD }\end{array}$ & Antiarrítmico & Amiodarona & $7,2 \mu \mathrm{M}-2,5 \mathrm{mM}$ & - & $\begin{array}{c}\text { Dzimiri e Almotrefi } \\
\text { (1993) }\end{array}$ \\
\hline Ensaio do MTT & $\begin{array}{l}\text { Viabilidade celular/ } \\
\text { citotoxicidade }\end{array}$ & Anti-inflamatório & $\begin{array}{l}\text { Indometacina, } \\
\text { ketoprofeno, } \\
\text { ibuprofeno etc. }\end{array}$ & $10 \mu \mathrm{M}$ & - & Allen et al. (1991) \\
\hline
\end{tabular}

DNA: ácido desoxirribonucleico; NADH: nicotinamida adenina dinucleotídeo reduzida; NAD: nicotinamida adenina dinucleotídeo oxidada; *fator de indução; **revertentes/ $\mu$ g; ns: número de revertentes não significante. 


\section{CONCLUSÕES}

Embora a presença de fármacos no ambiente tenha sido relatada por diferentes grupos de pesquisa em diversos países, informações sobre os seus efeitos adversos em diferentes organismos e, principalmente, as concentrações consideradas limiares são ainda incipientes. Foram apresentadas neste trabalho as concentrações de fármacos quantificados em águas e efluentes brasileiros e compiladas informações sobre a toxicidade de tais contaminantes em nível aquático, celular e genético. Com base nisso, concluiu-se que as concentrações tóxicas observadas, equivalentes a $\mathrm{CE}_{50}$ ou $\mathrm{CL}_{50}$, foram de 10 a 100 vezes maiores que aquelas achadas no ambiente. Ainda, considerando os ensaios citotóxicos e genotóxicos, em sua maioria, viu-se que os fármacos na concentração usualmente encontrada no ambiente não apresentaram toxicidade significativa. Ensaios crônicos com elevada sensibilidade são os mais apropriados para investigar os riscos associados à presença de fármacos (ou de seus subprodutos) no ambiente. A baixa disponibilidade de dados relacionados ao efeito crônico dos fármacos sugere dificuldade em aplicar tais testes no monitoramento de amostras ambientais, uma vez que nesse caso os efeitos se referem à exposição prolongada $\mathrm{e}$ a doses cumulativas do agente.

\section{REFERÊNCIAS}

ABOU-EISHA, A. (2006) Evaluation of cytogenetic and DNA damage induced by the antibacterial drug, trimethoprim. Toxicology in Vitro, v. 20, n. 5, p. 601-607. https://doi.org/10.1016/j. tiv.2005.10.008

AL-HARBI, M.M. (1993) Effect of captopril on the cytological and biochemical changes induced by adriamycin. Food and Chemical Toxicology, v. 31, n. 3, p. 209-212. https://doi.org/10.1016/02786915(93)90095-G

ALLEN, C.N.; HARPUR, E.S.; GRAY, T.J.; HIRST, B.H. (1991) Toxic effects of non-steroidal anti-inflammatory drugs in a human intestinal epithelial cell line (HCT-8), as assessed by the MTT and neutral red assays. Toxicology in Vitro, v. 5, n. 3, p. 183-191. https://doi. org/10.1016/0887-2333(91)90016-7

AQUINO, S.F.; BRANDT, E.M.F.; CHERNICHARO, C.A.L. (2O13) Remoção de fármacos e desreguladores endócrinos em estações de tratamento de esgoto: revisão da literatura. Engenharia Sanitária e Ambiental, v. 18, n. 3, p. 187-204. http://dx.doi.org/10.1590/S141341522013000300002

BENOTTI, M.J.; TRENHOLM, R.A.; VANDERFORD, B.J.; HOLADY, J.C.; STANFORD, B.D.; SNYDER, S.A. (2009) Pharmaceuticals and endocrine disrupting compounds in U.S. drinking water. Environmental Science \& Technology, v. 43, n. 3, p. 597-603. https:// doi.org/10.1021/es801845a

BERGMAN, A.; HEINDEL, J.J.; JOBLING, S.; KIDD, K.A.; ZOELLER, T. (2013) Endocrine Disrupting Chemicals - 2012: An assessment of the state of the science of endocrine disruptors prepared by a group of experts for the United Nations Environment Programme and World Health Organization. Genebra: WHO/ UNEP. 296 p.

BILA, D.; DEZOTTI, M. (2003) Fármacos no meio ambiente. Química Nova, v. 26, n. 4, p. 523-530. http://dx.doi.org/10.1590/S010040422003000400015
BIRCH, G.F.; DRAGE, D.S.; THOMPSON, K.; EAGLESHAM, G.; MUELLER, J.F. (2015) Emerging contaminants (pharmaceuticals, personal care products, a food additive and pesticides) in waters of Sydney estuary, Australia. Marine Pollution Bulletin, v. 97, n. 1-2, p. 56-66. https://doi.org/10.1016/j. marpolbul.2015.06.038

BISTAN, M.; PODGORELEC, M.; LOGAR, R.M.; TISLER, T. (2O12) Yeast Estrogen Screen Assay as a Tool for Detecting Estrogenic Activity in Water Bodies. Food Technology Biotechnology, v. 50 n. 4 , p. 427-433.

BONASSI, S.; ZNAOR, A.; CEPPI, M.; LANDO, C.; CHANG, W.P.; HOLLAND, N.; KIRSCH-VOLDERS, M.; ZEIGER, E.; BAN, S.; BARALE, R.; BIGATTI, MP.; BOLOGNESI, C.; CEBULSKA-WASILEWSKA, A.; FABIANOVA, E.; FUCIC, A.; HAGMAR, L.; JOKSIC, G.; MARTELLI, A.; MIGLIORE, L.; MIRKOVA, E.; SCARFI, M.R.; ZIJNO, A.; NORPPA, H.; FENECH, M. (2007) An increased micronucleus frequency in peripheral blood Iymphocytes predicts the risk of cancer in humans. Carcinogenesis, v. 28, n. 3, p. 625-631. https://doi. org/10.1093/carcin/bgl177

BRANDT, E.M.F.; QUEIROZ, F.B.; AFONSO, R.J.C.F.; AQUINO, S.F.; CHERNICHARO, C.A.L. (2O13) Behaviour of pharmaceuticals and endocrine disrupting chemicals in simplified sewage treatment systems. Journal of Environmental Management, v. 128, p. 718-726. https://doi.org/10.1016/j.jenvman.2013.06.003

BRASIL. (2011) Ministério da Saúde. Portaria no 2.914, de 12 de dezembro de 2011. Normas e padrão de potabilidade da água destinada ao consumo humano. Brasil: Ministério da Saúde.

BRASIL. (2017) Ministério da Saúde. Portaria de Consolidação no 5, de 28 de setembro de 2017. Consolidação das normas sobre as ações e os serviços de saúde do Sistema Único de Saúde. Brasil: Ministério da Saúde. 
CARLSSON, C.; JOHANSSON, A.-K.; ALVAN, G.; BERGMAN, K.; KÜHLER, T. (2006) Are pharmaceuticals potent environmental pollutants? Part I: environmental risk assessments of selected active pharmaceutical ingredients. The Science of the Total Environment, v. 364, n. 1-3, p. 67-87. https://doi.org/10.1016/j.scitotenv.2005.06.035

CLEUVERS, M. (2003) Aquatic ecotoxicity of pharmaceuticals including the assessment of combination effects. Toxicology Letters, v. 142, n. 3, p. 185-194. https://doi.org/10.1016/s03784274(03)00068-7

COMISSÃO DAS COMUNIDADES EUROPEIAS. (1996) Technical guidance document in support of Commission Directive 93/67/EEC on risk assessment for new notified substances and Commission Regulation (EC) No 1488/94 on risk assessment for existing substances. Part II: Environmental Risk Assessment. Luxemburgo: Office for official publications of the European Communities.

COSTA, C.R.; OLIVI, P.; BOTTA, C.M.R.; ESPINDOLA, E.L.G. (2008) A toxicidade em ambientes aquáticos: discussão e métodos de avaliação. Química Nova, v. 31, n. 7, p. 1820-1830. http://dx.doi. org/10.1590/S0100-40422008000700038

DAUGHTON, C. (2002) Environmental Stewardship and Drugs as Pollutants. Environmental Protection Agency. The Lancet, v. 360, n. 9339, p. 1035-1036. https://doi.org/10.1016/S01406736(O2)11176-7

DELGADO, L.F.; CHARLES, P.; GLUCINA, K.; MORLAY, C. (2012) The removal of endocrine disrupting compounds, pharmaceutically activated compounds and cyanobacterial toxins during drinking water preparation using activated carbon-a review. The Science of the Total Environment, v. 435-436, p. 509-525. https://doi. org/10.1016/j.scitotenv.2012.07.046

DEODATO, E.L. (2009) Caracterização do potencial genotóxico e mutagênico de misturas 3:1 de nutrição parenteral voltadas para pacientes neonatos. Dissertação (Mestrado em Ciências Farmacêuticas) - Universidade Federal do Rio de Janeiro, Rio do Janeiro.

DEVI, P.S.; POLASA, H. (1987) Evaluation of the anti-inflammatory drug indomethacin, for its genotoxicity in mice. Mutation Research, v. 188, n. 4, p. 343-347. https://doi.org/10.1016/01651218(87)90011-5

DODD, M.C.; HUANG, C.H. (2004) Transformation of the antibacterial agent sulfamethoxazole in reactions with chlorine: kinetics, mechanisms, and pathways. Environmental Science \& Technology, v. 38, n. 21, p. 5607-5615. https://doi.org/10.1021/es035225z

DZIMIRI, N.; ALMOTREFI, A.A. (1993) Actions of amiodarone on mitochondrial ATPase and lactate dehydrogenase activities in guinea pig heart preparations. European Journal of Pharmacology, v. 242, n. 2, p. 113-118. https://doi.org/10.1016/00142999(93)90070-X

FARRÉ, M.; PÉREZ, S.; KANTIANI, L.; BARCELÓ, D. (2008) Fate and toxicity of emerging pollutants, their metabolites and transformation products in the aquatic environment. Trends in Analytical Chemistry, v. 27, n. 11, p. 991-1007. https://doi.org/10.1016/j. trac.2008.09.010
FERRARI, B.; PAXÉUS, N.; LO GIUDICE, R.; POLLIO, A.; GARRIC, J. (2003) Ecotoxicological impact of pharmaceuticals found in treated wastewaters: study of carbamazepine, clofibric acid, and diclofenac. Ecotoxicology and Environmental Safety, v. 55, n. 3, p. 359-370. https://doi.org/10.1016/s0147-6513(O2)00082-9

GARTISER, S.; HAFNER, C.; KRONENBERGER-SCHÄFER, K.; HAPPEL, O.; TRAUTWEIN, C.; KÜMMERER, K. (2012) Approach for detecting mutagenicity of biodegraded and ozonated pharmaceuticals, metabolites and transformation products from a drinking water perspective. Environmental Science and Pollution Research International, v. 19, n. 8, p. 3597-3609. https://doi.org/10.1007/s11356012-0925-x

GHISELLI, G. (2006) Avaliação da Qualidade das Águas Destinadas ao Abastecimento Público na Região de Campinas: Ocorrência e Determinação dos Interferentes Endócrinos (IE) e Produtos Farmacêuticos e de Higiene Pessoas (PFHP). 190f. Tese (Doutorado em Ciências) - Universidade Estadual de Campinas, Campinas.

GIRI, A.K.; SIVAM, S.S.; KHAN, K.A. (1992) Sister-chromatid exchange and chromosome aberrations induced by paracetamol in vivo in bone-marrow cells of mice. Mutation Research, v. 278, n. 4, p. 253258. https://doi.org/10.1016/S0165-1218(10)80004-7

GUIMARÃES, T.S. (2008) Deteç̧ão e quantificação dos hormônios sexuais $17 \beta$ - Estradiol (E2), Estriol (E3), Etrona (E1) e $17 \alpha$ - Etinilestradiol (EE2) em água de abastecimento: Estudo de caso da cidade de São Carlos, com vistas ao saneamento ambiental. Dissertação (Mestrado em Hidráulica e Saneamento) Universidade de São Paulo, São Carlos.

HOSSEINIMEHR, S.J.; KARAMI, M. (2005) Chemoprotective effects of captopril against cyclophosphamide-induced genotoxicity in mouse bone marrow cells. Archives of Toxicology, v. 79, n. 8, p. 482 486. https://doi.org/10.1007/s00204-005-0655-7

ISIDORI, M.; LAVORGNA, M.; NARDELLI, A.; PASCARELLA, L.; PARRELLA, A. (2005) Toxic and genotoxic evaluation of six antibiotics on non-target organisms. The Science of the Total Environment, v. 346, n. 1-3, p. 87-98. https://doi.org/10.1016/j. scitotenv.2004.11.017

IZUMI, K.; SANO, N.; OTSUKA, H.; KINOUCHI, T.; OHNISHI, Y. (1991) Tumor promoting potential in male F344 rats and mutagenicity in Salmonella typhimurium of dipyrone. Carcinogenesis, v. 12, n. 7, p. 1221-1225. https://doi.org/10.1093/carcin/12.7.1221

JARDIM, W.F; MONTAGNER, C.C:; PESCARA, I.C.; UMBUZEIRO G.A.; BERGAMASCO, A.M.D.; ELDRIDGE, M.L.; SODRÉ, F.F. (2O11) An integrated approach to evaluate emerging contaminants in drinking water. Separation and Purification Technology, v. 84, p. 3-8. http://dx.doi.org/10.1016/j.seppur.2011.06.020

KOLPIN, D.W.; FURLONG, E.T.; MEYER, M.T.; THURMAN, E.M.; ZAUGG, S.D.; BARBER, L.B.; BUXTON, H.T. (2002) Pharmaceuticals, hormones, and other organic wastewater contaminants in U.S. streams, 1999-2000: a national reconnaissance. Environmental Science \& Technology, v. 36, n. 6, p. 1202-1211. https://doi. org/10.1021/esO11055j 
KÜMMERER, K. (2010) Pharmaceuticals in the Environment. Annual Review of Environment and Resources, v. 35, p. 57-75. https:// doi.org/10.1146/annurev-environ-052809-161223

LI, J.; XU, L; SHI, Z.G.; HU, M. (2015) A novel two-dimensional liquid chromatographic system for the online toxicity prediction of pharmaceuticals and related substances. Journal of Hazardous Materials, v.293, p.15-20.https://doi.org/10.1016/j.jhazmat.2015.03.035

LIMA, D.R.; TONUCCl, M.C.; LIBÂNIO, M.; AQUINO, S.F. (2O17) Fármacos e desreguladores endócrinos em águas Brasileiras: ocorrência e técnicas de remoção. Engenharia Sanitária e Ambiental, v. 22, n. 6, p. 1043-1054. http://dx.doi.org/10.1590/s141341522017165207

LIMA, D.R.S.; AFONSO, R.J.C.F.; LIBÂNIO, M.; AQUINO, S.F. (2O14) Avaliação da remoção de fármacos e de desreguladores endócrinos em águas de abastecimento por clarificação em escala de bancada. Química Nova, v. 37, n. 5, p. 783-788. http://dx.doi. org/10.5935/0100-4042.20140126

MACHADO, K.C.; GRASSI, M.T.; VIDAL, C.; PESCARA, I.C.; JARDIM, W.F.; FERNANDES, A.N.; SODRÉ, F.F.; ALMEIDA, F.V.; SANTANA, J.S.; CANELA, M.C.; NUNES, C.R.O.; BICHINHO, K.M.; SEVERO, F.J.R. (2O16) A preliminary nationwide survey of the presence of emerging contaminants in drinking and source waters in Brazil. Science of the Total Environment, v. 572, p. 138-146. https://doi.org/10.1016/j. scitotenv.2016.07.210

MAGDALENO, A.; CARUSSO, S.; MORETTON, J. (2017) Toxicity and genotoxicity of three antimicrobials commonly used in veterinary medicine. Bulletin of Environmental Contamination Toxicology, v. 99, n. 3, p. 315-320. https://doi.org/10.1007/s00128-017-2091-9

MELO, S.A.S.; TROVÓ, A.G.; BAUTITZ, I.R.; NOGUEIRA, R.F.P. (2009) Degradação de fármacos residuais por processos oxidativos avançados. Química Nova, v. 32, n. 1, p. 188-197. http://dx.doi. org/10.1590/S0100-40422009000100034

MONTAGNER, C.C.; JARDIM, W.F. (2011) Spatial and Seasonal Variations of Pharmaceuticals and Endocrine Disruptors in the Atibaia River, São Paulo State (Brazil). Journal of the Brazilian Chemical Society, v. 22, n. 8, p. 1452-1462. http://dx.doi.org/10.1590/ S0103-50532011000800008

MOREIRA, D.S.; AQUINO, S.F.; AFONSO, R.J.C.F.; SANTOS, E.P.P.C.; PÁDUA, V.L. (2009) Occurrence of endocrine disrupting compounds in water sources of Belo Horizonte Metropolitan Area, Brazil. Environmental Technology, v. 30, n. 10, p. 1041-1049. https:// doi.org/10.1080/09593330903052830

MOREIRA, M.; AQUINO, S.F.; COUTRIM, M.; SILVA, J.; AFONSO, R. (2011) Determination of endocrine-disrupting compounds in waters from Rio das Velhas, Brazil, by liquid chromatography/high resolution mass spectrometry (ESI-LC-IT-TOF/MS), Environmental Technology, v. 32, n. 11-12, p. 1409-1417. https://doi.org/10.1080/095 93330.2010 .537829

MOSMANN, T. (1983) Rapid colorimetric assay for cellular growth and survival: application to proliferation and cytotoxicity assays. Journal of Immunological Methods, v. 65, n. 1-2, p. 55-63. https://doi. org/10.1016/0022-1759(83)90303-4
NIETO, E.; HAMPEL, M.; GONZÁlEZ-ORTEGÓN, E.; DRAKE, P.; BLASCO, J. (2016) Influence of temperature on toxicity of single pharmaceuticals and mixtures, in the crustacean $A$. desmarestii. Journal of Hazardous Materials, v. 313, p. 159-169. https://doi. org/10.1016/j.jhazmat.2016.03.061

ONWUAMAH, C.K.; EKAMA, S.O.; AUDU, R.A.; EZECHI, O.C.; POIRIER, M.C.; ODEIGAH, P.G.C. (2014) Exposure of Allium cepa root cells to zidovudine or nevirapine induces cytogenotoxic changes. PLOS One, v. 9, n. 3, p. 1-7. https://doi.org/10.1371/journal.pone.0090296

ORGANIZAÇÃO MUNDIAL DA SAÚDE (OMS). (2O11) Guidelines for Drinking-water Quality. 4. ed. Genebra: OMS. 564 p.

ORGANIZAÇÃOMUNDIALDASAÚDE(OMS).(2012)Pharmaceuticals in Drinking-water. Genebra: Public Health and Environment Water, Sanitation, Hygiene and Health. Disponível em: <http://apps. who.int/iris/bitstream/10665/44630/1/9789241502085_eng.pdf>. Acesso em: jul. 2012.

ORGANIZAÇÃO MUNDIAL DA SAÚDE (OMS). (2014) Antimicrobial Resistance: global report on surveillance. WHO Library Cataloguingin-Publication Data. Genebra: OMS. 257p.

ORGANIZAÇÃO MUNDIAL DA SAÚDE (OMS). (2016) Antimicrobial Resistance. Fact sheet. Organização Mundial da Saúde. Disponível em: <www.who.int/mediacentre/factsheets/fs194/en/>. Acesso em: set. 2016.

ORGANIZAÇÃO MUNDIAL DA SAÚDE (OMS). (2017) Guidelines for drinking-water quality. 4. ed. Genebra: Organização Mundial da Saúde.

PARRELLA, A.; LAVORGNA, M.; CRISCUOLO, E.; ISIDORI, M. (2O13) Mutagenicity, Genotoxicity and Estrogenic Activity of River Porewaters. Environmental Contamination and Toxicology, v. 65, n. 3, p. 407-420. https://doi.org/10.1007/s00244-013-9928-y

PEREIRA, R.O. (2011) Formação de subprodutos do estrona e 17ß- estradiol na oxidação utilizando cloro e ozônio em água. Tese (Doutorado em Ciências) - Universidade de São Paulo, São Carlos.

PHILIPOSE, B.; SINGH, R.; KHAN, K.A.; GIRI, A.K. (1997) Comparative mutagenic and genotoxic effects of three propionic acid derivatives ibuprofen, ketoprofen and naproxen. Mutation Research, v. 393, n. 1-2, p. 123-131. https://doi.org/10.1016/s1383-5718(97)00095-8

QUEIROZ, F.B.; BRANDT, E.M.F.; AQUINO, S.F.; CHERNICHARO, C.A.L.; AFONSO, R.J.C.F. (2012) Occurrence of pharmaceuticals and endocrine disruptors in raw sewage and their behavior in UASB reactors operated at different hydraulic retention times. Water Science \& Technology, v. 66, n. 12, p. 2562-2569. https://doi. org/10.2166/wst.2012.482

QUINTANA, J.B.; RODIL, R.; LÓPEZ-MAHÍA, P.; MUNIATEGUILORENZO, S.; PRADA-RODRÍGUEZ, D. (2010) Investigating the chlorination of acidic pharmaceuticals and by-product formation aided by an experimental design methodology. Water Research, v. 44, n. 1, p. 243-255. https://doi.org/10.1016/j. watres.2009.09.018 
QUINTÃO, F.J.O.; FREITAS, J.R.L.; MACHADO, C.F.; AQUINO, S.F.; SILVA, S.Q.; AFONSO, R.J.C.F. (2016) Characterization of metformin by-products under photolysis, photocatalysis, ozonation and chlorination by high-performance liquid chromatography coupled to high-resolution mass spectrometry. Rapid Communications in Mass Spectrometry, v. 30, n. 21, p. 2360-2368. https://doi.org/10.1002/ rcm.7724

RAIMUNDO, C.C.M. (2007) Ocorrência de interferentes endócrinos e produtos farmacêuticos nas águas superficiais da bacia do rio Atibaia. Dissertação (Mestrado em Química) - Universidade Estadual de Campinas, Campinas.

RIGOBELLO, E.S. (2012) Avaliação da remoção de diclofenaco e formação de subprodutos em tratamento de água. Tese (Doutorado em Ciências) - Universidade de São Paulo, São Carlos.

ROZAS, O:; VIDAL, C:; BAEZA, C.; JARDIM, W.F.; ROSSNER, A:; MANSILLA, H.D. (2016) Organic micropollutants (OMPs) in natural waters: Oxidation by $\mathrm{UV} / \mathrm{H}_{2} \mathrm{O}_{2}$ treatment and toxicity assessment. Water Research, v. 98, p. 109-118. https://doi.org/10.1016/j.watres.2016.03.069

SANDERSON, H.; BRAIN, R.A.; JOHNSON, D.J.; WILSON, C.J.; SOLOMON, K.R. (2004) Toxicity classification and evaluation of four pharmaceuticals classes: antibiotics, antineoplastics, cardiovascular, and sex hormones. Toxicology, v. 203, n. 1-3, p. 27-40. https://doi. org/10.1016/j.tox.2004.05.015

SANTOS-SILVA, T.G.; MONTAGNER, C.C.; MARTINEZ, C.B.R. (2018) Evaluation of caffeine effects on biochemical and genotoxic biomarkers in the neotropical freshwater teleost Prochilodus lineatus. Environmental Toxicology and Pharmacology, v. 58, p. 237242. https://doi.org/10.1016/j.etap.2018.02.002

SODRÉ, F.F.; PESCARA, I.C:; MONTAGNER, C.C.; JARDIM, W.F. (2010) Assessing selected estrogens and xenoestrogens in Brazilian surface waters by liquid chromatography-tandem mass spectrometry. Microchemical Journal, v. 96, n. 1, p. 92-98. https://doi. org/10.1016/j.microc.2010.02.012

SOUZA, B.P.; LIMA, D.R.S.; AQUINO, S.F.; QUARESMA, A.V.; BAÊTA, B.E.L.; LIBÂNIO, M. (2018) Oxidação de fármacos por cloro e formação de subprodutos em amostras aquosas em escala de bancada. Engenharia Sanitária e Ambiental, v. 23, n. 2, p. 207-216. http://dx.doi.org/10.1590/s1413-41522018155335

SOUZA, N.C. (2011) Avaliação de Micropoluentes Emergentes em Esgotos e Águas Superficiais. 166p. Tese (Doutorado em Engenharia Civil) - Universidade Federal do Ceará, Fortaleza.

STULTS, D.M.; KILLEN, M.W.; PIERCE, A.J. (2014) The sister chromatid exchange (SCE) assay. In: KEOHAVONG, P.; GRANT, S.G. (orgs.) Molecular Toxicology Protocols, Methods in Molecular Biology. Totowa, NJ: Humana Press. v. 1105. 633 p. cap. 32.

STUMPF, M.; TERNES, T.A.; WILKEN, R.D.; RODRIGUES, S.V.; BAUMANN, W. (1999) Polar drug residues in sewage and natural waters in the state of Rio de Janeiro, Brazil. The Science of the Total Environment, v. 225, n. 1-2, p. 135-141. https://doi.org/10.1016/s00489697(98)00339-8

TERNES, T.A.; MEISENHEIMER, M.; MCDOWELL, D.; SACHER, F.; BRAUCH, H.-J.; HAIST-GULDE, B.; PREUSS, G.; WILME, U.; ZULEISEIBERT, N. (2002) Removal of pharmaceuticals during drinking water treatment. Environmental Science \& Technology, v. 36, n. 17, p. 3855-3863. https://doi.org/10.1021/es015757k

TERNES, T.A.; STUMPF, M.; MUELLER, J.; HABERER, K.; WILKEN, R.D.; SERVOS, M. (1999) Behavior and occurrence of estrogens in municipal sewage treatment plants--I. Investigations in Germany, Canada and Brazil. The Science of the Total Environment, v. 225, n. 1-2, p. 81-90. https://doi.org/10.1016/ s0048-9697(98)00334-9

TICE, R.R.; AGURELL, E.; ANDERSON, D.; BURLINSON, B.; HARTMANN, A.; KOBAYASHI, H.; MIYAMAE, Y.; ROJAS, E.; RYU, J.C.; SASAKI, Y.F. (2000) Single cell gel/comet assay: guidelines for in vitro and in vivo genetic toxicology testing. Environmental and Molecular Mutagenesis, v. 35, n. 3, p. 206-221. https://doi.org/10.1002/ (sici)1098-2280(2000)35:3\%3C206::aid-em8\%3E3.0.co;2-j

U.S. ENVIRONMENTAL PROTECTION AGENCY (USEPA). (2001) Removal of Endocrine Disruptor Chemicals Using Drinking Water Treatment Processes. Washington, D.C.: USEPA. Disponível em: <http://nepis.epa.gov/Adobe/PDF/30004HGG.pdf>. Acesso em: 15 jan. 2016 